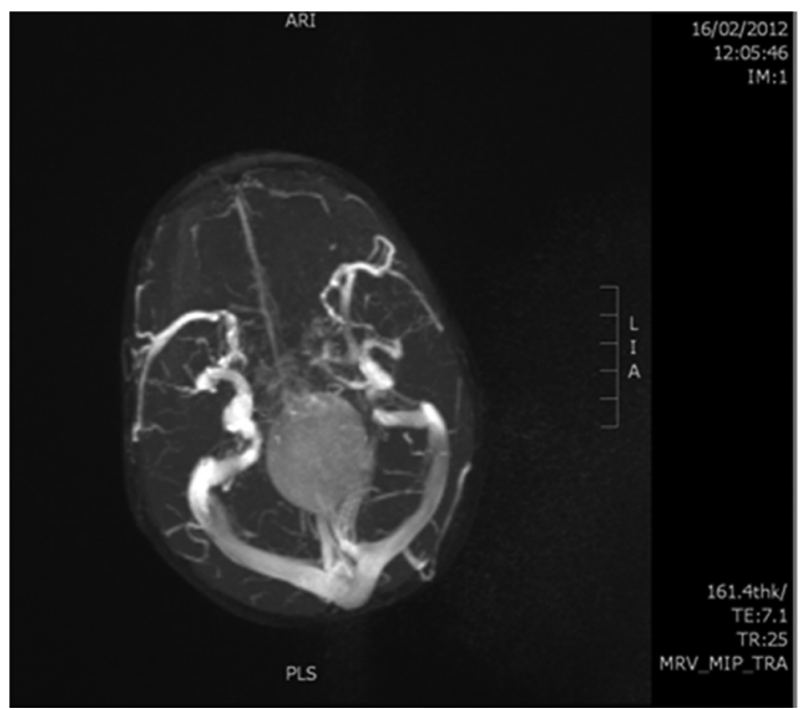

Abstract P55 Figure 1

Results 5 months old child with atrial septal defect with partial anomalous pulmonary venous drainage was seen in cardiology clinic and based on failure to thrive with congenital heart defects and respiratory distress, he was admitted to the paediatric ward with the impression of heart failure. As there was congenital heart defect so the heart failure was thought to be from the congenital heart defect and it was difficult to manage as well. Later on, examination picked up a cranial bruit, MRI brain showed vein of galen malformation. Child was transferred to tertiary neurosurgery and glue embolization was performed which was uneventful.

Conclusion This case illustrates the presentation of vein of galen with heart failure in a child with congenital heart defects. There was cardiac defect so that was thought to be the cause of heart failure but later on examination picked up cranial bruit and MRI brain confirmed the vein of galen malformation.

\section{P56 OBESITY AND ACCOMPANYING RISK FACTORS IMPORTANT FOR THE ONSET OF ATEROSCELLOSIS}

Gordana, Milorad Grujic Ilic, Jerkan*, Milorad Jerkan. Health Center Nis, Nis, Serbia

10.1136/archdischild-2019-epa.411

Obesity is one of the significant risk factors in the development of atherosclerosis, the most common metabolic disorder which the world's health organization classified as an epidemic disease.

Aim Point to frequency of obesity in children, risk factors significant for the onset of atherosclerosis in obese children and association of these factors.

Methods 2069 children aged 2-19 were examined. Body mass index (BMI) (Body weight/Body height $\left.{ }^{2}\right)\left(\mathrm{kg} / \mathrm{m}^{2}\right)$ was calculated. Tables of international standards for BMI of children corresponding to BMI in adults were used for the assessment of nutrition. Obesity is classified with BMI> 30 $\mathrm{kg} / \mathrm{m}^{2}$. Blood pressure $(\mathrm{BP} / \mathrm{mmHg})$, systolic and diastolic was measured. Total cholesterol (TC), high density lipoprotein cholesterol (HDL-C), triglycerides (TG) concentrations were determined. Low density lipoprotein (LDL-C), nonHDL cholesterol (TC-HDL-C) were calculated. 2016 ESC/EAS guidelines for the management and European guidelines for prevention, diagnosis and treatment of high BP in children and adolescents (2010) were used to estimate the results.

Results There were $10.45 \%$ obese and $15.6 \%$ overweight children. BP (Systolic, Diastolic) were significantly higher in obese $(105.71 / 65.82)$ than in normal weight children (94/58.79). In the obese there was a really significant connection between BMI and BP, Systilic $(r=0.625)$ and diastolic $(r=0.541)$. TC, LDL-C, TG and nonHDL-C values were significantly higher in obese $(4.25 ; 2.53 ; 1.13 ; 3.02$ $\mathrm{mmol} / \mathrm{l})$ than in normal weight $(4.06 ; 2.31 ; 0.92 ; 2.73$ $\mathrm{mmol} / \mathrm{l})$. HDL-C values were significantly lower $(<0.001)$. The percentage of children with increased values of SBP, DBP, and SBP and DBP was higher in obese children $(15.35 \% ; 6.64 \%$ : $5.81 \%)$ than in normal weight $(1.26 \%$; $1.08 \% ; 0.42 \%)$.

The percentage of children with lipid and lipoprotein values which are a high risk factor for the development of cardiovascular diseases in adulthood was higher in obese children and also was the percentage of children with more associated values.

Conclusion Blood pressure values, lipids and lipoproteins values, which are significant risk factors for the onset of atherosclerosis, were higher in obese children. It is necessary to detect obese children on time and apply all preventive measures in its control and elimination. The chosen doctor plays a major role in this. It is necessary to have continuous parents and teachers education about proper children diet and the role of physical activity, smoking and alcoholism prevention. The whole community should also be involved.

\section{P57 PATHOGENETIC VALUE OF ENDOTHELININ IN PREDICTING THE CLINICAL COURSE OF CARDIOMYOPATHY IN CHILDREN}

1,2Dilorom Akhmedova*, ${ }^{2}$ Nilufar Akhmedova, ${ }^{1}$ Alima Matkarimova. ${ }^{1}$ Republican Specialized Scientific and Practical Medical Center of Pediatrics, Tashkent, Uzbekistan; ${ }^{2}$ Tashkent Pediatric Medical Institute, Tashkent, Uzbekistan

\subsection{6/archdischild-2019-epa.412}

Relevance The study of biochemical changes in cardiovascular diseases is one of the urgent problems of pediatric cardiology. Biochemical markers of myocardial damage include cardiospecific proteins - troponin, endothelin and myoglobin, which provide some assistance in specifying an unfavorable cardiomyopathic prognosis.

Purpose of the study To study the pathogenetic significance of endothelin in predicting the clinical course of cardiomyopathy in children.

Materials and methods 54 children with diagnoses of dilated and hypertrophic cardiomyopathy were hospitalized in cardioreumatology departments of the Republican Specialized Scientific and Practical Medical Center of Pediatrics in Tashkent and the Republican Children's Multidisciplinary Medical Center in Nukus. The age of the examined children ranged from 1 year to 17 years and averaged $7.1 \pm 0.7$ years. Biochemical methods included the determination of endothelin in the serum by immunofluorescence analysis on an IMAXIZ 